\title{
Hyperextended call note repertoire of the endemic Madagascar treefrog Boophis madagascariensis (Rhacophoridae)
}

\author{
P. M. Narins ${ }^{1}$, E. R. Lewis ${ }^{2}$ and B. E. McClelland ${ }^{3}$ \\ ${ }^{1}$ Department of Physiological Science, 621 Charles E. Young Drive South, Box 951606, University of California, Los Angeles, CA 90095-1606, U.S.A. \\ ${ }^{2}$ Department of EE \& CS, University of California, Berkeley, CA 94720 , U.S.A. \\ ${ }^{3}$ Department of Psychology, University of Texas at Austin, Austin, TX 78712, U.S.A. \\ (Accepted 30 April 1999)
}

\begin{abstract}
Vocalizations of Boophis madagascariensis (Rhacophoridae) males were recorded in a mid-elevation rain forest in eastern Madagascar. Call notes made by males of this species were classified into 28 types. This represents the largest known call repertoire of any amphibian. The calls range widely in spectral characteristics from a narrowband, nearly pure-tone to broadband 'rip' notes, to even broader band, pulsatile 'iambic' notes consisting of up to 23 pulses. Even considering all 'iambic' notes as variants of one type, there remain eight distinct call notes produced by this species. Morphological analysis of the vocal musculature of $B$. madagascariensis revealed no obvious adaptations for unusual glottal flexibility or function. Playback studies using a subset of the call notes as stimuli were carried out in the animals' natural habitat to determine the functional significance of several of the call notes. At the lowest playback levels, there was a significant tendency for males to produce rip notes in immediate response to either rip or iambic note stimuli. At the higher playback levels, we identified one sequence of iambic notes that consistently evoked a significant iambic note response from males. A permutation test on call note transitions during spontaneous calling revealed that call note pairs occurred inconsistently and unpredictably. The evolutionary significance of an extended vocal repertoire, matched counter-calling and a random call note production scheme is discussed.
\end{abstract}

Key words: vocalizations, playback studies, anuran, amphibian, counter-calling, Boophis madagascariensis

\section{INTRODUCTION}

Males of most frogs and toads typically produce a small number of stereotyped, repetitive vocalizations that have a restricted number of functions. At least five major call types were originally recognized by Bogert (1960) including the mating call, the territorial call, the distress call, the warning call and the release call. Generally, a frog's mating call serves more than one function and thus it is now referred to as the advertisement call (Littlejohn, 1977; Wells, 1977). In addition, males of some territorial species produce a call when another frog, usually a male, is detected within their territory. This vocalization is distinct from the advertisement call and has been referred to as the territorial or 'encounter' call (McDiarmid \& Adler, 1974) or the 'short-distance aggressive call' (Salthe \& Mecham, 1974). In modern usage, these two call types have been subsumed by the more general term 'aggressive' call (e.g. Wells \& Schwartz, 1984b; Given, 1987; Wagner, 1989; Grafe, 1995; Narins et al., 1998).

The advertisement call often consists of a single note or a series of notes that is repeated quasi-periodically for many hours and can be highly stereotyped in its structure. That is, the call notes are often redundant and are emitted with little spectral, temporal or amplitude variation (Narins \& Capranica, 1977; Brenowitz, Wilczynski \& Zakon, 1984; Schwartz \& Wells, 1984a; Harrison \& Littlejohn, 1985). These factors presumably confer increased localizability and noise immunity upon the calls. Both features are highly advantageous in large assemblages of vocalizing frogs, often characterized by extremely intense levels of ambient sounds during the evening, when most anuran amphibians are actively calling (Narins, 1982; Gerhardt \& Klump, 1988; Narins \& Zelick, 1988).

Many anurans have advertisement calls that consist of a single repeated note or trill. However, some species have more complex advertisement calls consisting of multiple notes (Littlejohn, 1977; Wells, 1988). For example, males of the hylid frog Smilisca sila are capable of producing single or multiple-note calls, but in the latter case the notes are nearly identical (Tuttle \& Ryan, 1982). In contrast, the advertisement call of the 


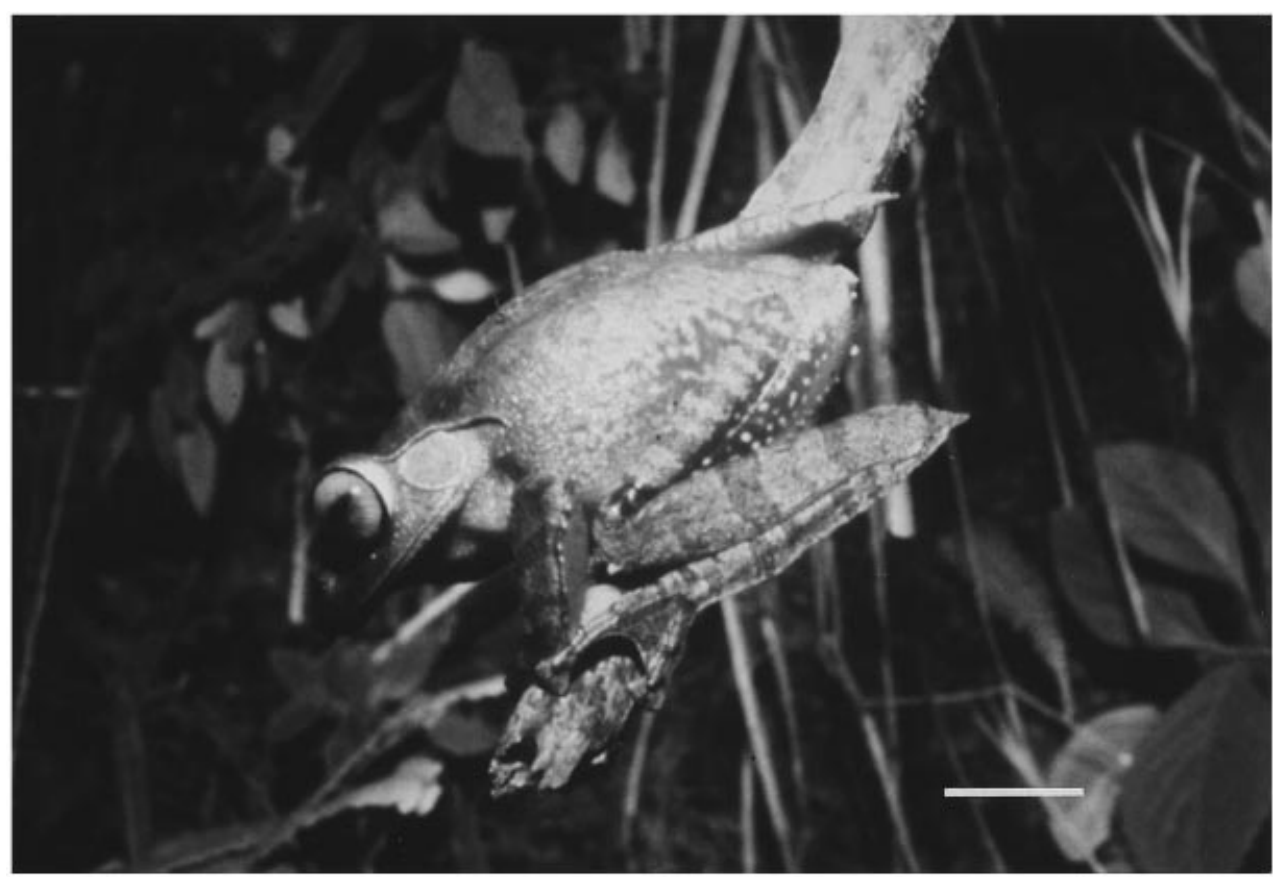

Fig. 1. Male Boophis madagascariensis on perch in typical calling orientation, Ranomafana National Park, Madagascar. Scale bar $=10 \mathrm{~mm}$.

neotropical leptodactylid Physalaemus pustulosus consists of a whine note followed by a variable number of chuck notes, which are spectrally and temporally distinct from the whine note (Rand \& Ryan, 1981; Ryan, 1985). Complexity is evident in the vocalizations of Hyla ebraccata as well, in which males respond to conspecific calls by increasing the proportion of their multi-note and aggressive calls (Schwartz \& Wells, 1984a; Wells, 1989).

An additional aspect of the vocal repertoire of several New World species is the use of either graded or multiple types of aggressive calls in escalating interactions among males. For example, $H$. ebraccata, $H$. microcephala and $H$. phlebodes all exhibit graded aggressive call systems in which the length of the introductory note of the aggressive call increases with decreasing distance between interacting males, while the pulse rate of these calls decreases as duration increases (Schwartz \& Wells, 1984a,b, 1985; Schwartz, 1986). Similar graded aggressive calls have been described in Pseudacris crucifer by Schwartz (1989) and in Hyperolius marmoratus by Grafe (1995). Other frogs, including Rana clamitans (Wells, 1978), R. catesbeiana (Capranica, 1968) and $R$. virgatipes (Given, 1987) produce at least three distinct types of calls used in aggressive interactions of differing degrees of escalation.

In more recent studies, both the striped and nonstriped morphs of Polypedates leucomystax, a rhacophorid frog common in Peninsular Malaysia, seem to be able to produce advertisement calls with at least three distinct notes, suggesting yet greater complexity (Narins et al., 1998). Moreover, preliminary call analysis for two populations of the non-striped morph of the same species located in Northern Thailand reveals a repertoire of at least four distinct call types in one population (E. J. Garcia \& P. M. Narins, pers. obs.) and at least nine call types in the other. (J. Christensen-Dalsgaard, T. A. Ludwig \& P. M. Narins, pers. obs.).

Boophis madagascariensis (Rhacophoridae) is endemic to Madagascar where it is restricted to the eastern half of the island. It is a large (45-80 mm snout-vent length) brown treefrog with conspicuous dermal flaps ('spines') on the elbows and heels (Fig. 1); males are smaller than females (Peters, 1874). During the day, these frogs may use retreat sites in the leaf-axils of large plants (Blommers-Schlösser, 1979) or remain crouched down on the forest floor (Preston-Mafham, 1991), but at night males emerge to call from shallow water, at the border of pools or slow-moving streams or from elevated perch sites on the vegetation (Glaw \& Vences, 1994; Andreone, 1996). The frogs call from sunset until 01:00-02:00 during November. Male vocalizations are easily recorded because these animals are not readily disturbed by the sounds of investigators in their vicinity. Studies of regurgitated pellets and food remains of the Madagascar long-eared owl Asio madagascariensis have shown that nocturnal predation by owls is high on frogs in the genus Boophis (Goodman, Creighton \& Raxworthy, 1991).

Initial observations of a small assemblage of calling male Boophis madagascariensis suggested that the call repertoire of this animal was extraordinarily large, and that emission of certain call note types (which we labelled 'rips' and 'iambics') by one male tended to elicit the same call note type from neighbouring males. Moreover, small groups of male frogs form choruses emitting nearly synchronous iambic calls triggered by one chorus leader, which consistently prefaced his 
iambic call with another call note or call note sequence. Based on these observations, we established three goals: (1) to record and characterize the vocal repertoire of B. madagascariensis; (2) to use acoustic playback experiments with natural call notes as stimuli to test the hypothesis that rip call notes and iambic call notes tend to be answered with call notes of the same kind; (3) to perform acoustic playback experiments to test the hypothesis that the preface note emitted by the chorus leader was used by the follower frogs as a timing cue for their vocalizations. To test this last hypothesis, we recorded the compound call of a chorus leader, then rerecorded it three times on the stimulus tape - once with the initial segment (preface note) and iambic components together (intact call), once with only the iambic component, and once with only the preface note. We predicted that if the initial segment were used as a timing cue by the follower frogs, there would be increased synchronization to those call stimuli that contained the initial segment relative to those call stimuli that lacked this feature.

\section{MATERIALS AND METHODS}

\section{Study area}

Field recordings and playback experiments were conducted during October 1993 at a site about $0.8 \mathrm{~km}$ east of the entrance to Ranomafana National Park $\left(21^{\circ} 18^{\prime} \mathrm{S}\right.$, $47^{\circ} 18^{\prime} \mathrm{E}$ ), approx. $250 \mathrm{~km}$ south of Antananarivo, Madagascar. Most of the park area is mountainous and contains relatively undisturbed lowland rainforest, cloud forest and high plateau forest. At the study site (altitude $900 \mathrm{~m}$ a.s.1.), several species of frogs called from the ground along the roadside or from the emergent vegetation up to several metres above the road. Ambient temperature and relative humidity were consistently between $18-22{ }^{\circ} \mathrm{C}$ and $88-95 \%$, respectively, although ambient temperature at the park may range from 3.0 to $35.1^{\circ} \mathrm{C}$ (Nicoll \& Langrand, 1989; Andreone, 1994). All experiments were carried out between 18:45 and 00:25 local time, when calling activity was most intense.

\section{Recording of vocalizations and playback experiments}

Calling males of Boophis madagascariensis were located in their natural habitat. Ambient temperature, relative humidity, a description of the calling site, estimate of nearest-neighbour distances and any vocal interactions with neighbouring males were noted for each individual studied. Two minutes of spontaneous vocalizations were registered with a directional microphone (AudioTechnica AT-835 or AKG CK8) placed $10-35 \mathrm{~cm}$ from each calling male and recorded onto a portable cassette recorder (Sony Walkman Pro WM D6C). All recordings were made using low-noise tape (TDK Type II). For one male, $90 \mathrm{~min}$ of spontaneous calling was recorded, and for another pair of males located within several metres of one another, $135 \mathrm{~min}$ of calling interactions were recorded in an attempt to capture a large proportion of the animals' call note repertoire.

For the playback experiments, we broadcast acoustic stimuli consisting of natural call note sequences (see below) using the Sony Walkman driving a speakeramplifier (Calrad 20-257) and a 10-cm diameter loudspeaker fixed at the end of a boom on a tripod. The loudspeaker was placed $110 \mathrm{~cm}$ from each calling male. The males' calls were registered with a directional microphone (Audio-Technica AT-835) mounted at the end of an extendible boom on a second tripod. The stimuli were recorded on one channel of a stereo tape-recorder (Marantz PMD 430), while the male's vocalizations were recorded simultaneously on the second channel.

Four stimuli consisting of natural call notes and call note sequences were used in the playback experiments. The four stimuli and their note timings are illustrated in Fig. 2. Stimulus 1 comprised a natural 7-pulse iambic note (Fig. $3 \mathrm{~m}$ ). On the stimulus tape we re-recorded this note 4 times during a 6.1-s (on) period, which was followed an 11.5-s (off) period. This 17.6-s sequence was repeated 10 times during a 3-min (stimulus active, or $s a$ ) period. The $s a$ period was followed by a 2 -min period of no stimulus (spontaneous activity, or $s p$ period). Stimulus 1 was then re-broadcast to the test male for additional 3-min periods, but at progressively higher playback levels. For all stimuli, mean sound pressure levels at the eardrum of the male under test were incremented in discrete steps and could take on the following values: 69.7, 77.9, 84.9, 91.5 and $95.9 \mathrm{~dB}$ SPL. The sound pressure levels were calibrated using a precision sound level meter (GenRad 1982) to measure the stimulus SPL at $1.1 \mathrm{~m}$ from the loudspeaker, the known distance from the loudspeaker to the test male, and assuming spherical spreading. Each 3-min sa period was followed by a 2-min $s p$ period. Stimulus 2 was a single short rip note (Fig. 3c) that we copied 4 times during the $6.5 \mathrm{~s}$ on period, followed by a $12.1 \mathrm{~s}$ off period. Thus, the repetition period for stimulus 2 was $18.6 \mathrm{~s}$. As in stimulus 1 , each 3 -min $s a$ period was followed by a 2-min $s p$ period.

\section{Testing of call-timing hypothesis}

To test the hypothesis that the preface note serves as a timing cue by the leader, we recorded the leader's complete call note complex (preface note plus iambic call notes), then created a sequence of three call elements: (1) complete complex, (2) iambic note only, (3) preface note only. The presentation of the iambic note by itself tests whether this note alone is sufficient to trigger the highly synchronized response from the followers. The presentation of the preface note alone tests whether the highly synchronized response to the iambic note within the complete complex was simply a delayed response to the preface note.

Stimulus 3 consisted of 3 distinct call elements 


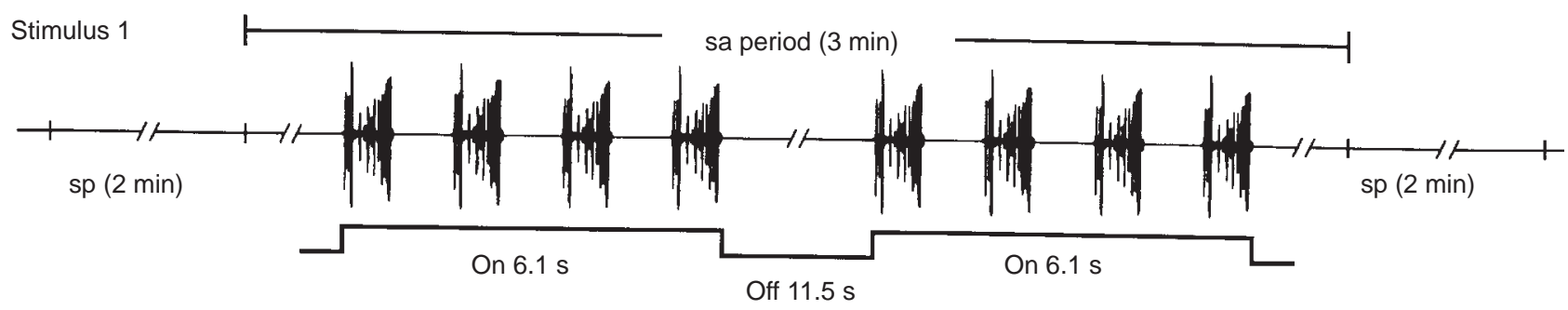

Stimulus 2
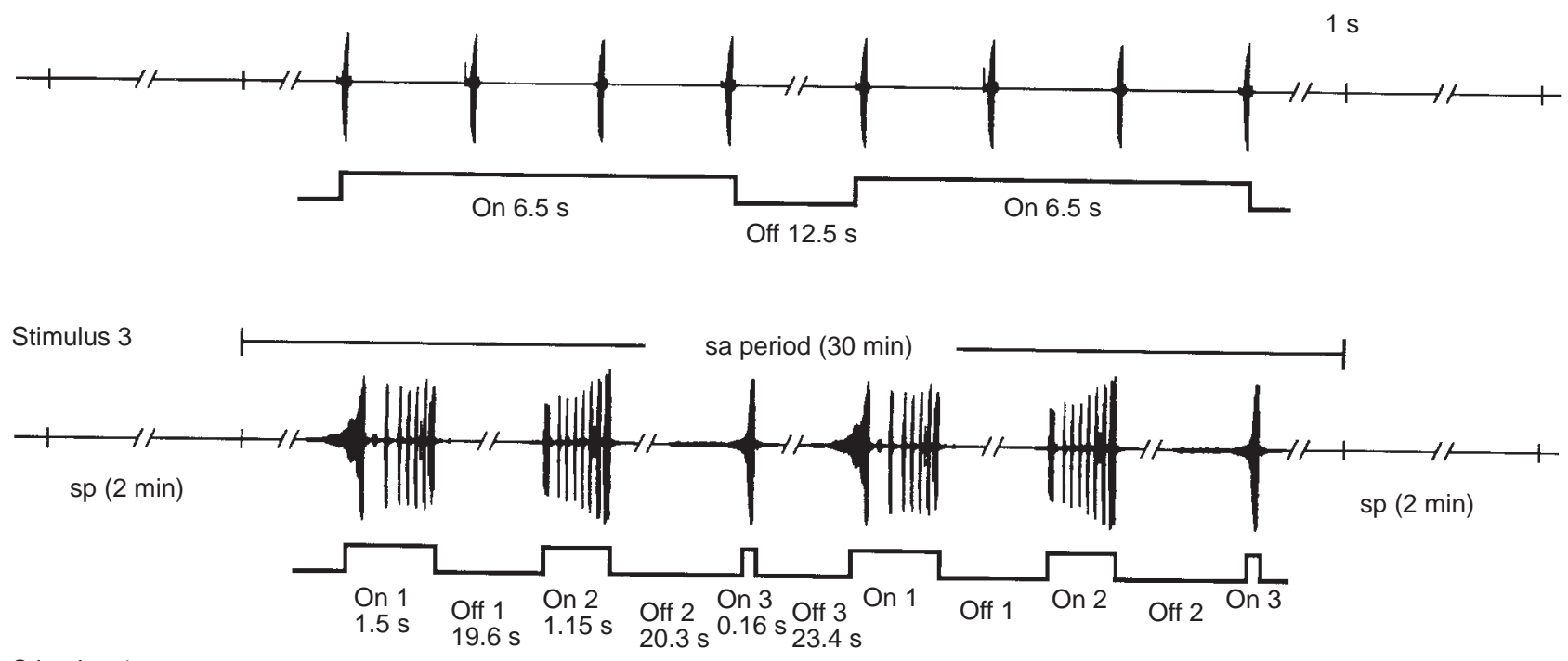

Stimulus 4

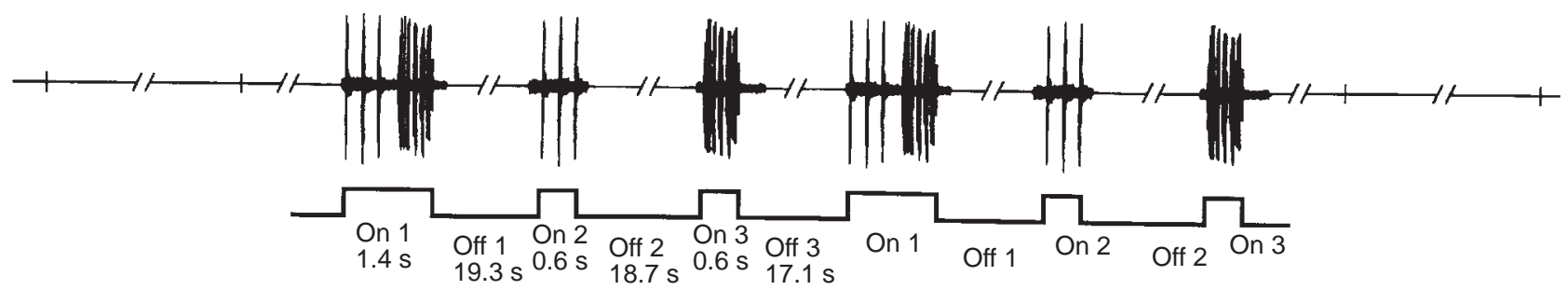

Fig. 2. Oscillograms and timing of the four acoustic stimuli used in the playback experiments. For details, see text. $\mathrm{sp}=$ spontaneous activity, the period during which no stimulus was presented; sa = stimulus active period, during which the stimulus was presented.

presented sequentially and repeated for $30 \mathrm{~min}$. First was the complete complex consisting of a long rip note (Fig. 3f) followed immediately by a 6-pulse iambic note (Fig. 31) and by $19.6 \mathrm{~s}$ of silence; call element 2 was a single 8-pulse iambic note (Fig. 3n) followed by $20.3 \mathrm{~s}$ of silence, and call element 3 was a single, long 'rip' (preface) note. Each sequence of three call elements was followed by $23.4 \mathrm{~s}$ of silence. Stimulus 4 had the same overall temporal structure as stimulus 3 , but the call elements consisted of: (1) 3 quick 'toc' notes (Fig. 3a) followed immediately by a 5-pulse iambic note (Fig. 3k), i.e. the complete complex; (2) 3 quick toc notes alone (which are considered the preface notes in this case); (3) a 5-pulse iambic note alone.

\section{Data analysis}

Call notes were analysed using a DSP Sonagraph (Kay
5500) using a transform size and an analysing filter bandwidth of either 100 points and $300 \mathrm{~Hz}$ (calls $3 \mathrm{a}$ and 3b), 200 points and $150 \mathrm{~Hz}$ (calls $3 \mathrm{c}$ and 3d) or 512 points and $59 \mathrm{~Hz}$ (all other calls). Call note timing was measured to the nearest $3.13 \mathrm{~ms}$ and call note frequency to the nearest $20 \mathrm{~Hz}$. Voltage waveforms were printed on a Gray scale printer (Kay 5510) directly from the sonagraph.

We first recorded the number and types of call notes produced during $90 \mathrm{~min}$ of spontaneous calling by an individual male. Notes were categorized both by ear and by inspection of their temporal and spectral waveforms. For the playback studies, we recorded the number and types of notes produced during each portion of the stimulus sequence. Numbers of notes evoked by different sections of the stimulus were compared using either the Student's $t$-test or the $\chi^{2}$ test. A criterion of $P<0.05$ was used for statistical significance. Two types of analyses were performed: (1) a microanalysis - the 

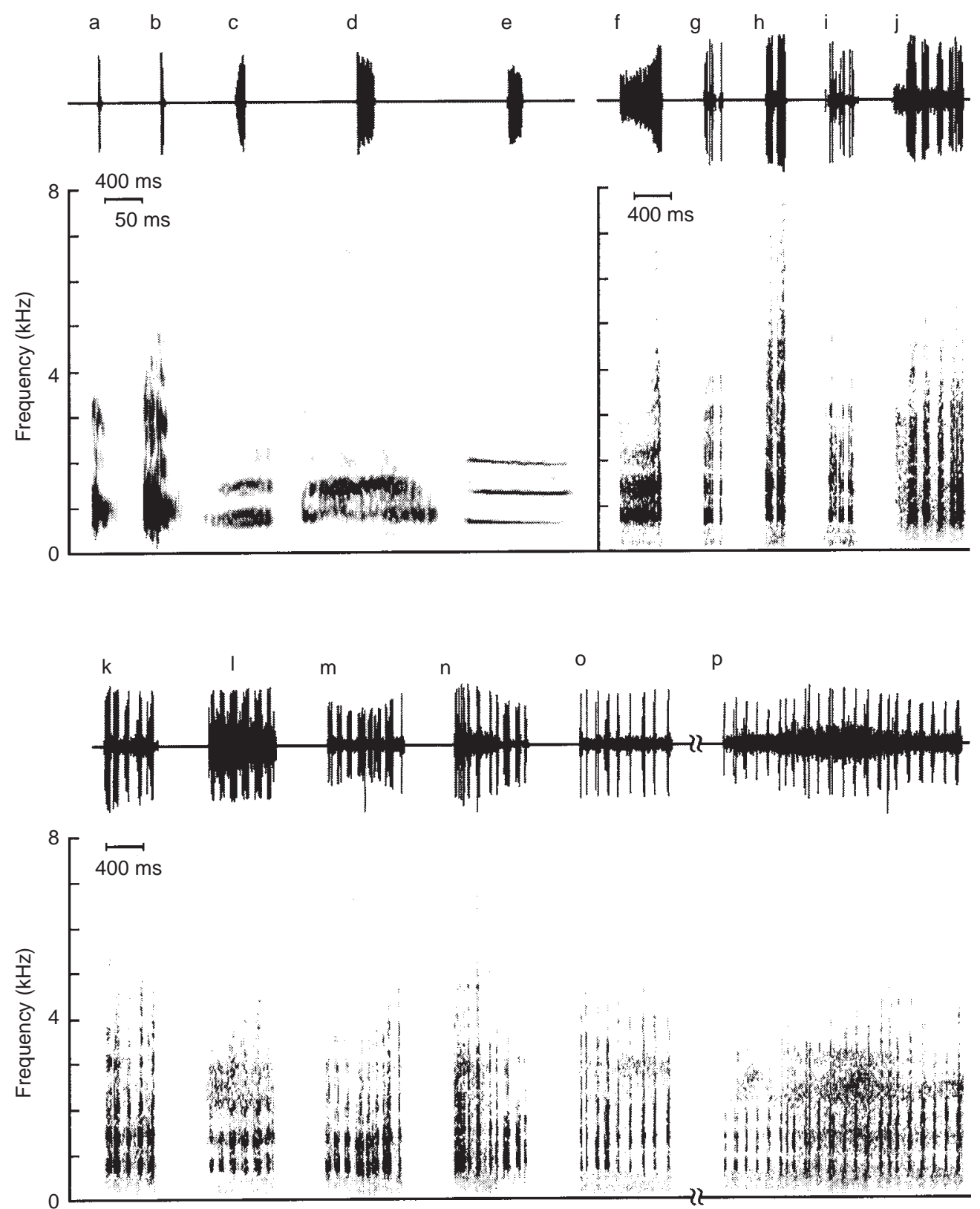

Fig. 3. Waveforms and sound spectrograms of representative call notes produced by males of Boophis madagascariensis. a, toc note; $b$, short click note; c, short rip note; d, loud click note; e, tone-like note with a fundamental frequency of $670 \mathrm{~Hz}$; $\mathrm{f}$, long rip note; g, creak note; $h-p$, iambic (I) notes with increasing numbers of pulses: (h) $I_{2}$, (i) $I_{3}$, (j) $I_{4}$, (k) $I_{5}$, (l) $I_{6}$, (m) $I_{7}$, (n) $I_{8}$, (o) $I_{9}$, (p) $I_{23}$. Except for $I_{21}$, all notes from $I_{10}$ to $I_{22}$ were also produced, but are not illustrated. Analysis filter bandwidth: a, and b: $300 \mathrm{~Hz}$; c, d: $150 \mathrm{~Hz}$; all other spectrograms: $59 \mathrm{~Hz}$. Ambient recording temperatures ranged from 18 to $22^{\circ} \mathrm{C}$. Time scale for sound spectrograms a-e has been magnified to provide increased temporal resolution.

comparison of the number of notes evoked from the test male during the on and off periods measured in seconds or fractions of a second; (2) macroanalysis - the comparison of the number of notes evoked from the test male during the stimulus active and post-stimulus (spontaneous) periods, measured in minutes.

Spontaneous call note sequences were checked for preferred pairs of notes using a permutation test described by Adams \& Anthony (1996). This procedure consists of recording a natural sequence of 100 consecutive B. madagascariensis vocalizations from an individual male and assigning every note to 1 of 5 groups, A-E (see Results). Each of the 99 pairs of sequential notes is then entered in a $5 \times 5$ matrix and subsequently these 100 notes are selected at random, forming in this way a new 100 -note sequence. Two hundred such 100-note sequences are so formed, and for each of the 25 possible sequential pairs, a frequency distribution is generated. The actual number of note pairs in the original (natural) sequence is then compared to the frequency distribution for the randomized sequences. If that number falls either within the 

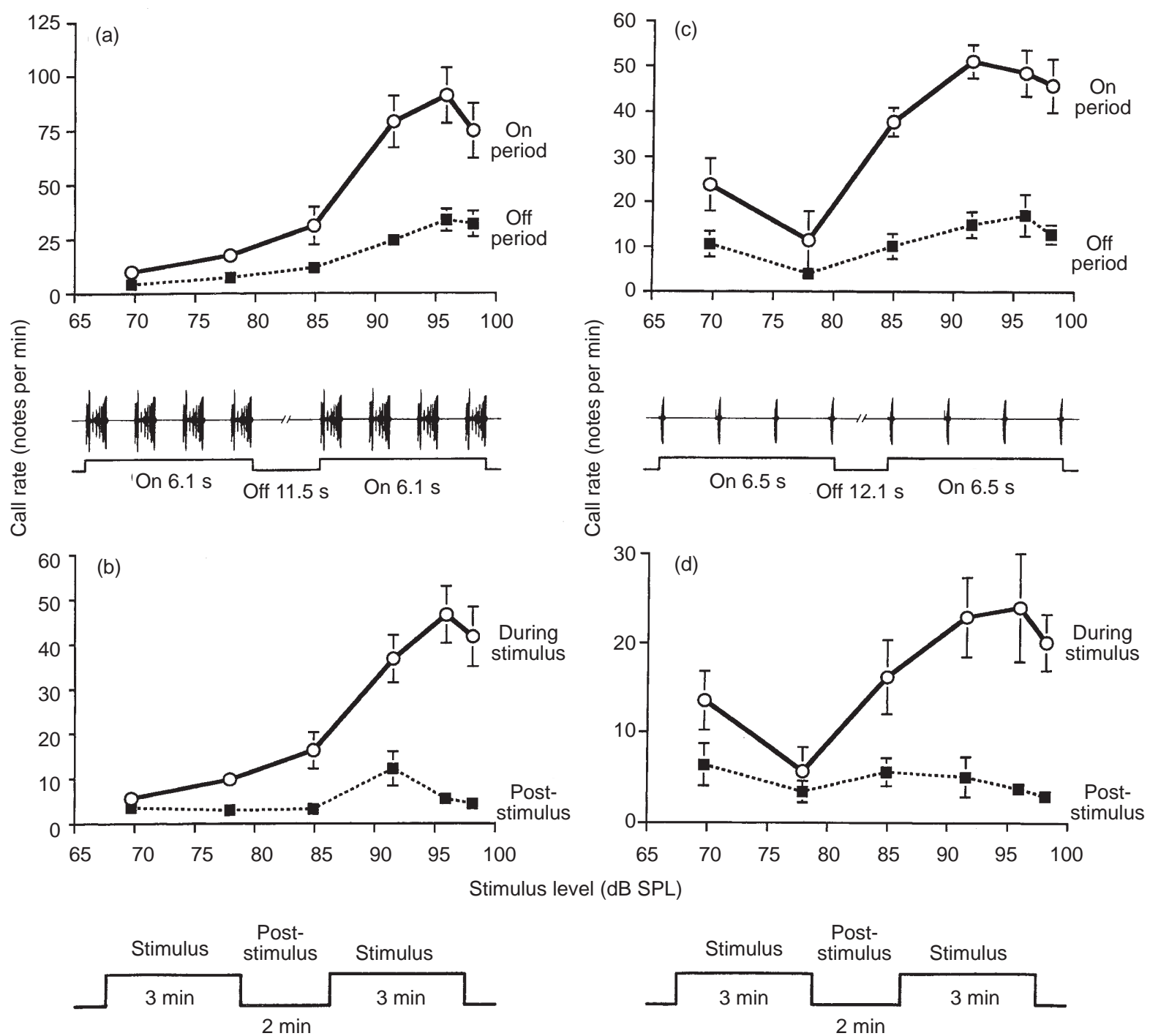

imulus level (dB SPL)

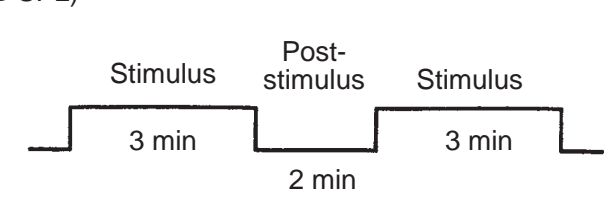

Fig. 4. Playback results for stimulus 1 and 2 presented at increasing levels. (a), (c) Microanalysis comparing the mean call note rates $( \pm \mathrm{SE}$ ) produced during the on periods and the off periods of stimulus 1 and 2, respectively. (b), (d). Macroanalysis comparing the call note rates produced during the entire duration of stimulus presentation and the post-stimulus periods of stimulus 1 and 2 , respectively. Both stimuli cause an increase in evoked call rate with increasing playback intensity, but neither stimulus was effective at increasing call rate during the post-stimulus period. Ambient temperature for the spontaneous calling: $18^{\circ} \mathrm{C}$.

lowest $0.025 \%$ or the highest $0.025 \%$ of the distribution, its frequency of occurrence is deemed either significantly less or significantly greater than would have been expected by chance. All data were subjected to the Bonferroni test to adjust for multiple comparisons.

\section{Morphometric measurements}

One male $B$. madagascariensis was available for anatomical study. The animal had been fixed with formalin using standard methods and stored in alcohol. Gross morphological features including SVL, head width, 'spine' lengths and tympanic membrane diameter were measured. The larynges and hyoid support cartilages were dissected and linear measurements of the larynx including glottal slit (aditus laryngis), and laryngeal length and width were made with vernier callipers to the nearest $0.01 \mathrm{~mm}$.

\section{RESULTS}

\section{Call types}

The calls of B. madagascariensis encompassed an extraordinarily wide range of sounds: they could be toc-like (Fig. 3a), click-like (Fig. 3b, d), tonal (Fig. 3e), 'creaky' (Fig. 3c,f,g) or pulsatile (Fig. 3h-p). In several cases, we observed males, under low light levels, producing these sounds as they were being recorded to convince ourselves that each of these notes actually was being emitted by males of this species.

Twenty-eight different call notes were recorded from 10 calling males of $B$. madagascariensis. No individual 
male produced all 28 call notes; this was the total number of distinct note types produced during a total of $24 \mathrm{~h}$ of recordings. For example, one male produced 14 distinct call notes, whereas all others produced fewer. In addition, none of the 10 males tested produced a pulsatile note with exactly 21 pulses (we refer to these pulsatile notes as 'iambic'; thus the $I_{21}$ note was not recorded in this study), although there is no a priori reason to suppose that males are incapable of generating this particular note since they produce all other iambic notes from $\mathrm{I}_{2}$ to $\mathrm{I}_{23}$. Thus, it is likely that the entire call note repertoire for this species has not yet been completely documented. Even considering all the pulsatile sequences (Fig. 3h-p) as iambic variants with different numbers of pulses $\left(I_{2}-I_{23}\right)$, there remain eight distinct call notes emitted by the population of males studied (Narins \& Lewis, 1996).

\section{Effect of playback level}

Playback studies with both stimulus 1 and 2 broadcast at increasing playback levels resulted in increased calling rates from the males under test. Figure $4 \mathrm{a} \& \mathrm{c}$ show the results of a microanalysis, whereas Fig. $4 b$ \& d show the results of a macroanalysis of the responses of 10 males to stimulus 1 and nine males to stimulus 2, respectively. Both analyses reveal similar results: for low stimulus playback levels, the evoked call note rate is low; as the stimulus playback level is increased, the evoked call note rate increases and at the highest stimulus playback levels, the evoked call note rate again decreases. We observed no off period or post-stimulus period call note rate dependence on the prior stimulus playback level, and moreover, the evoked rates in all cases tested are consistently higher than the non-evoked rates (Figs 4a-d). This lack of inter-trial 'memory' showed that stimulus trials with one male at successively higher playback levels are independent of previous trial playback levels.

A macroanalysis of the responses to stimulus 3 and 4 is shown in Fig. 5. The histograms indicate that for both stimuli and for both playback levels tested, the males' evoked call rates were reduced below their spontaneous rates. Moreover, the macroanalysis for the responses to these stimuli revealed no significant difference $(P>0.05)$ between call note rates between $s a$ and $s p$ periods. Stimulus 3 and 4 differ from stimulus 1 and 2 in that each member of the former pair consists of a series of three different call notes whereas the each of the latter pair consists of four repetitions of the same call note. Thus in one sense, stimulus 1 and 2 are less natural than stimulus 3 and 4 (see results of call sequence analyses). Given the extremely short on times for stimulus 3 and 4 , a microanalysis of the responses to these stimuli was not warranted.

\section{Call timing analysis}

For the next analysis, we partitioned all the call note

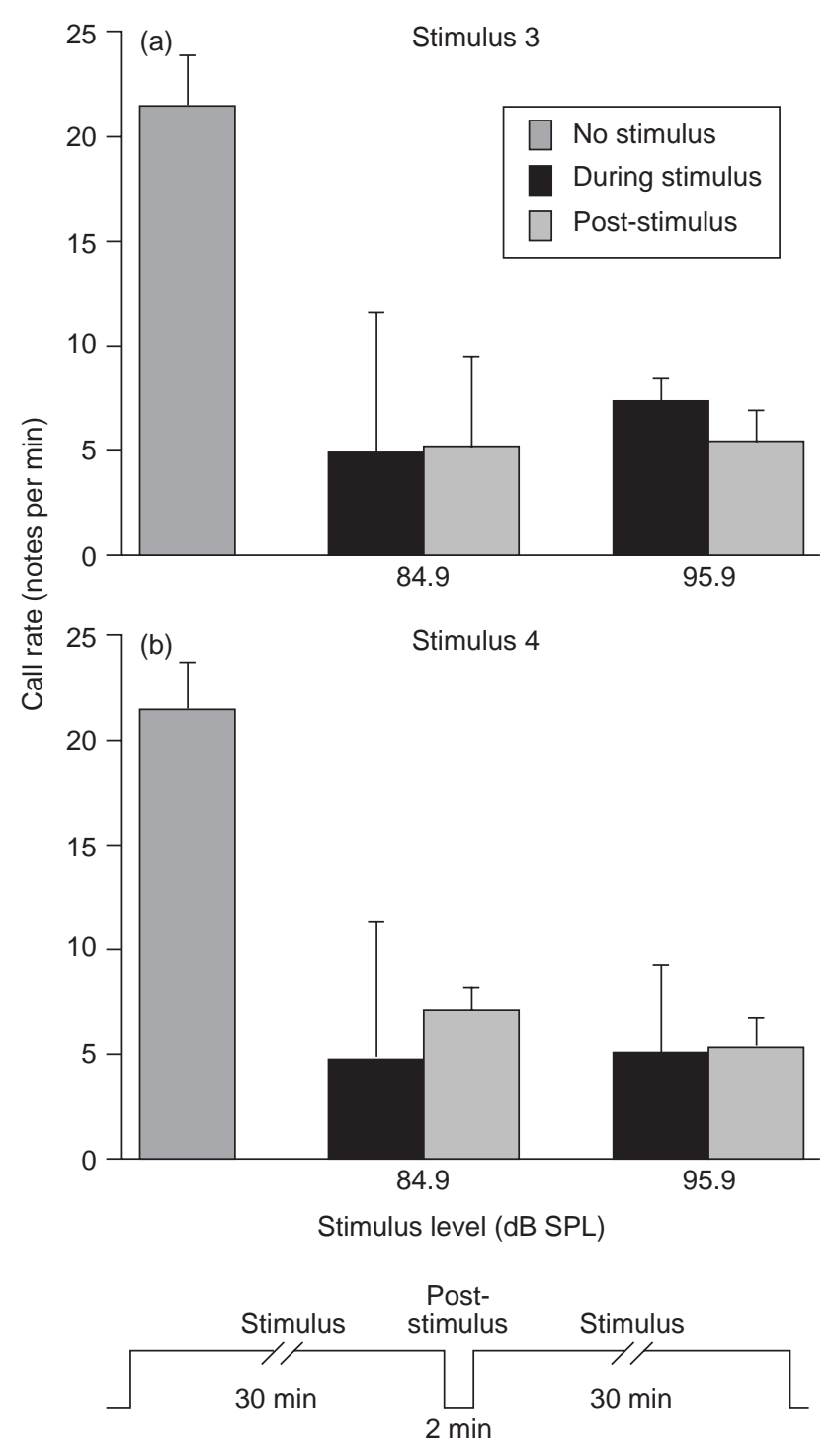

Fig. 5. Macroanalysis of responses to (a) stimulus 3 and (b) stimulus 4, comparing call note rates during and post-stimulus. Stimulus levels are measured at the position of the frog.

types into two groups: the first group contained all the rip and creak notes (Fig. 3c, f, g) which we collectively term 'rips' and the second group consisted of the iambic call notes (Fig. 3h-p). We examined the nature of the frogs' responses to our four stimuli (Fig. 2) as a function of playback level. Figure 6 shows the responses to stimulus 1 for 10 frogs tested. The rates of rip and iambic responses both increase with increasing stimulus level. The iambic responses are clustered close to the $s a$ period (note slight delay); the rip responses are more diffuse, with the rate of rip response being highest after the $s a$ period (possibly because the subjects were producing iambics during the $s a$ period and cannot produce both kinds of call notes at once). Clearly, as the stimulus playback level was increased, the number of iambic responses coincident with or immediately following the stimulus increased whereas the number of rip responses occurring at this time appeared to be uncorrelated with 

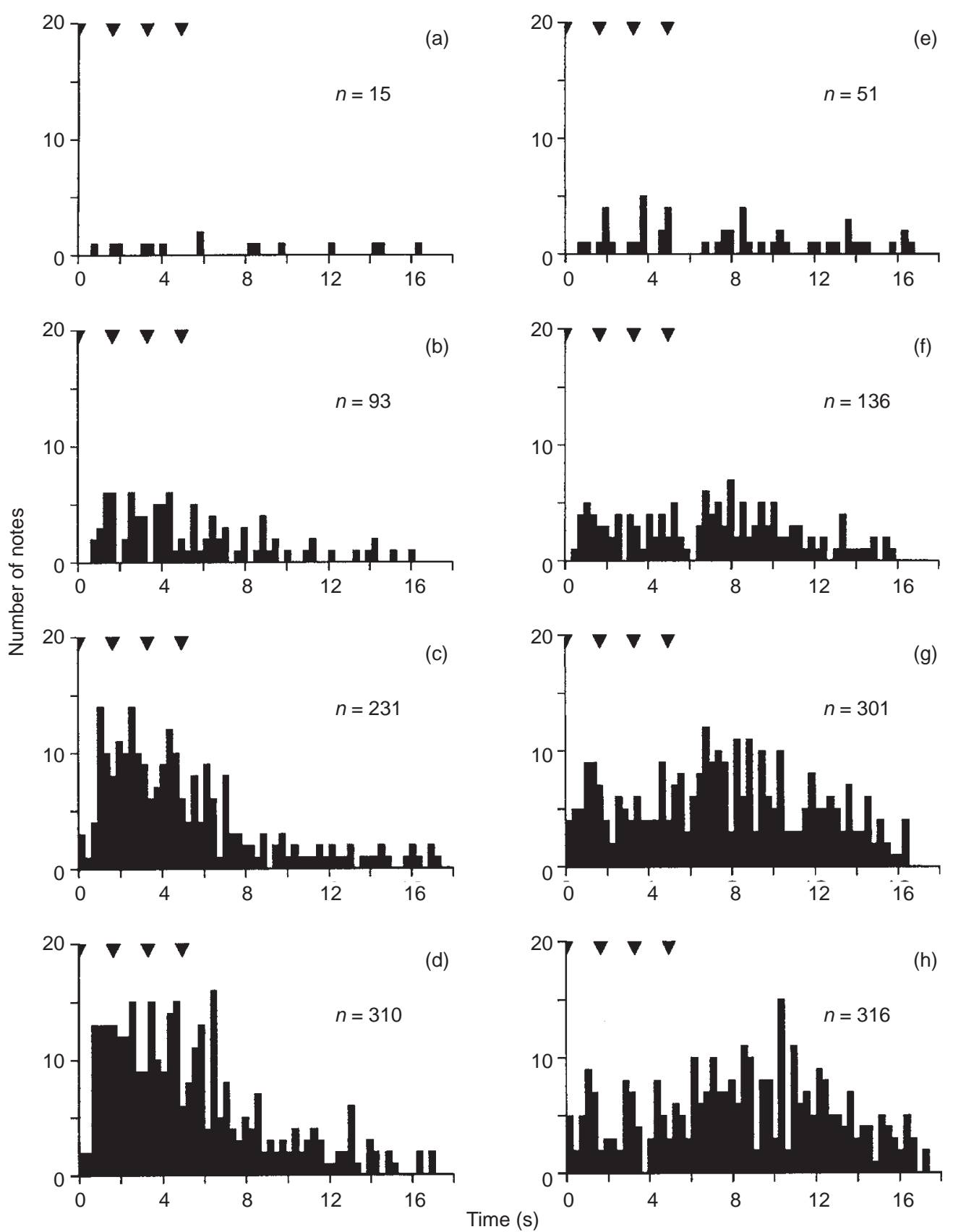

Fig. 6. Period histograms illustrating the iambic and rip responses to stimulus 1 (iambic call notes) as a function of playback level: (a) level 3, (b) level 4, (c) level 5, (d) level 6. Data are combined from 10 subjects. Inverted triangles indicate the onset times of each of the four iambic call notes during the $6.1 \mathrm{~s}$ stimulus on time. Left, onset times of iambic responses; right, onset times of rip responses; stimulus period 17.6 s. Playback levels (dB SPL) are given in the text. Bin widths of the histograms, $250 \mathrm{~ms}$.

the playback level of stimulus 1 . The males showed a tendency to respond to stimulus 2 in a manner similar to stimulus 1 (Fig. 7), but appeared to be less responsive to stimulus 2 on the whole (note vertical scale). The iambic responses to the rip notes in stimulus 2 are not as distinctly clustered as they were for iambic stimuli (e.g. Fig. 6).

It is clear from Figs $6 \& 7$ that iambic stimuli elicited responses other than iambic notes and rip stimuli elicited responses other than rip notes. Iambic notes in response to either kind of stimulus tended to be concentrated in the stimulus-on period (under the inverted triangles in Figs 6 \& 7); rip notes in response to either kind of stimuli tended to be distributed more broadly over the total stimulus period. Our impression that iambic notes and rip notes tended to elicit like notes in neighbouring frogs was based on the immediate responses that we heard. To test for those tendencies, therefore, we counted the responses during the stimulus on periods (the first $6 \mathrm{~s}$ for stimulus 1 , the first $8 \mathrm{~s}$ 
lambic responses
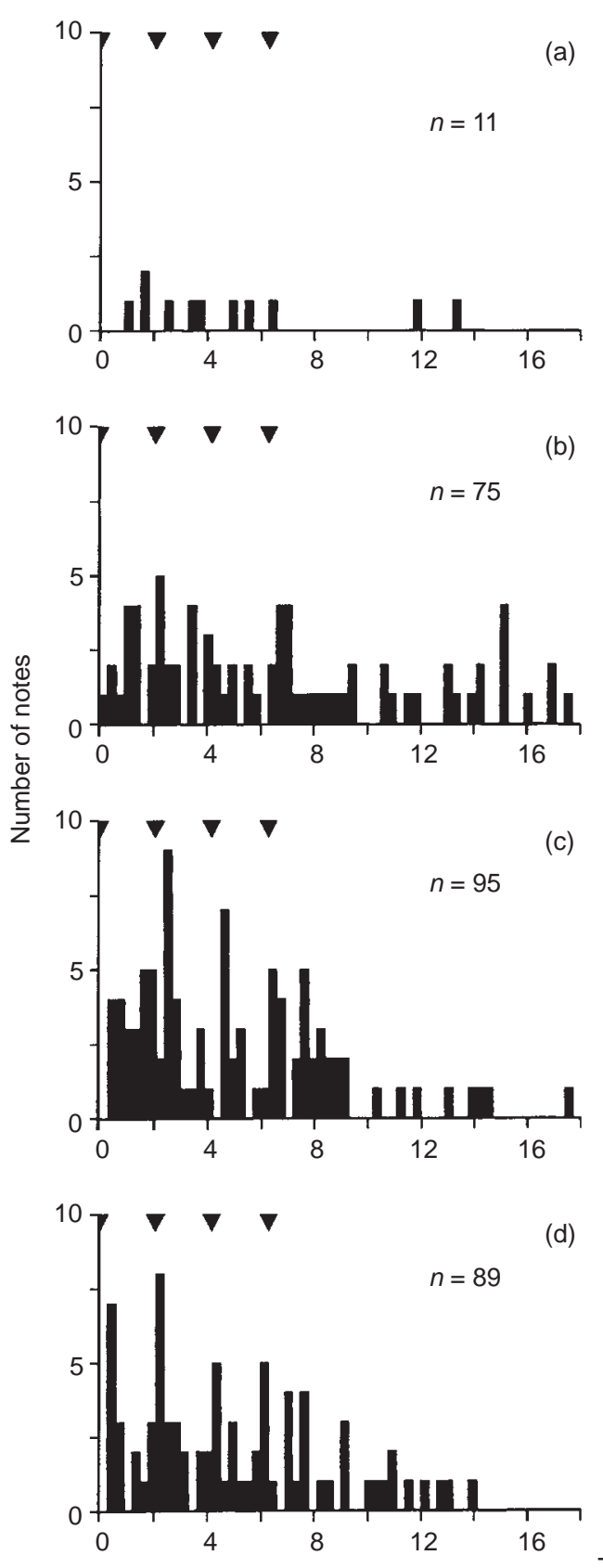

Rip responses
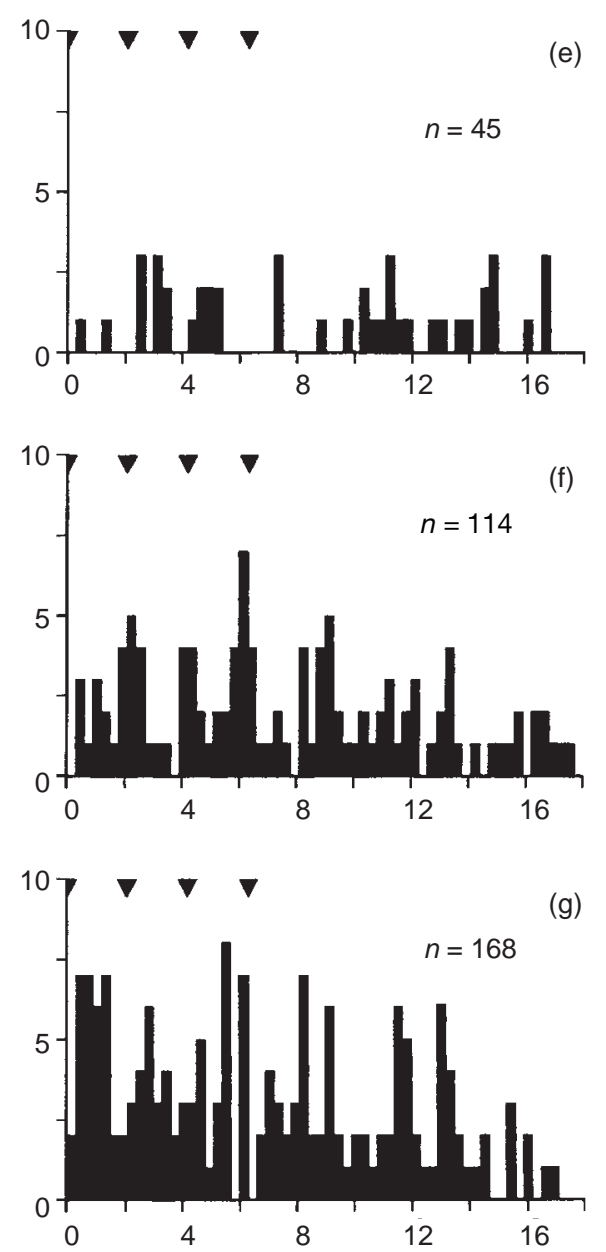

(h)

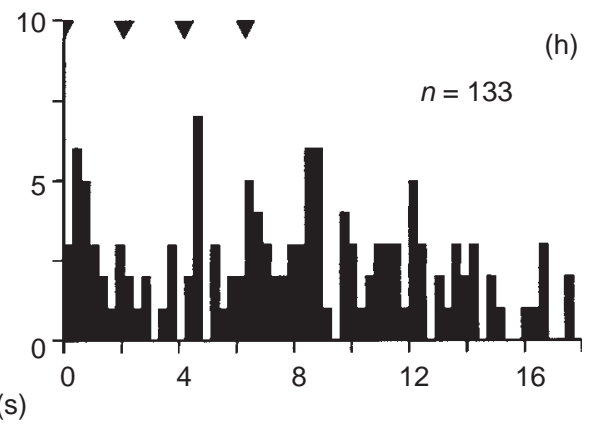

Fig. 7. Period histograms illustrating the iambic and rip responses of nine frogs to stimulus 2 (a series of short rip notes), as a function of the same playback levels as in Fig. 6. Data are combined from seven subjects. Inverted triangles indicate the onset times of each of the four rip call notes during the $6.5 \mathrm{~s}$ stimulus on time. Left, onset times of iambic responses; right, onset times of rip responses; Stimulus period 18.6 s. Playback levels (dB SPL) are given in the text. Bin widths of the histograms $250 \mathrm{~ms}$.

for stimulus 2). We then calculated the ratios of iambic-note responses to rip-note response in the first $6 \mathrm{~s}$ of stimulus 1 (four iambic notes), and for the first $8 \mathrm{~s}$ of stimulus 2 (four rip notes). Applying the $\chi^{2}$ test to the observed values and using equal evoked call rates as the expected values, we found that at the lowest stimulus level (level 3), there was a significant tendency $(P<0.001)$ to produce rip notes in immediate response to either stimulus 1 or 2 . At the next higher stimulus level (level 4), the apparent tendency to respond imme- diately in kind was not significant $(P>0.05$ for either stimulus). At stimulus level 5, the apparent tendency to respond immediately in kind was significant $(P<0.05)$ for stimulus 1 , but only marginally significant $(P<0.10$ for stimulus 2). At the highest stimulus level (level 6), the apparent tendency to respond immediately in kind to stimulus 1 was highly significant $(P<0.001)$. There was no apparent tendency to respond immediately in kind to stimulus 2 at that level. These results are summarized in Table 1 . Thus, the inclination to respond immediately in 


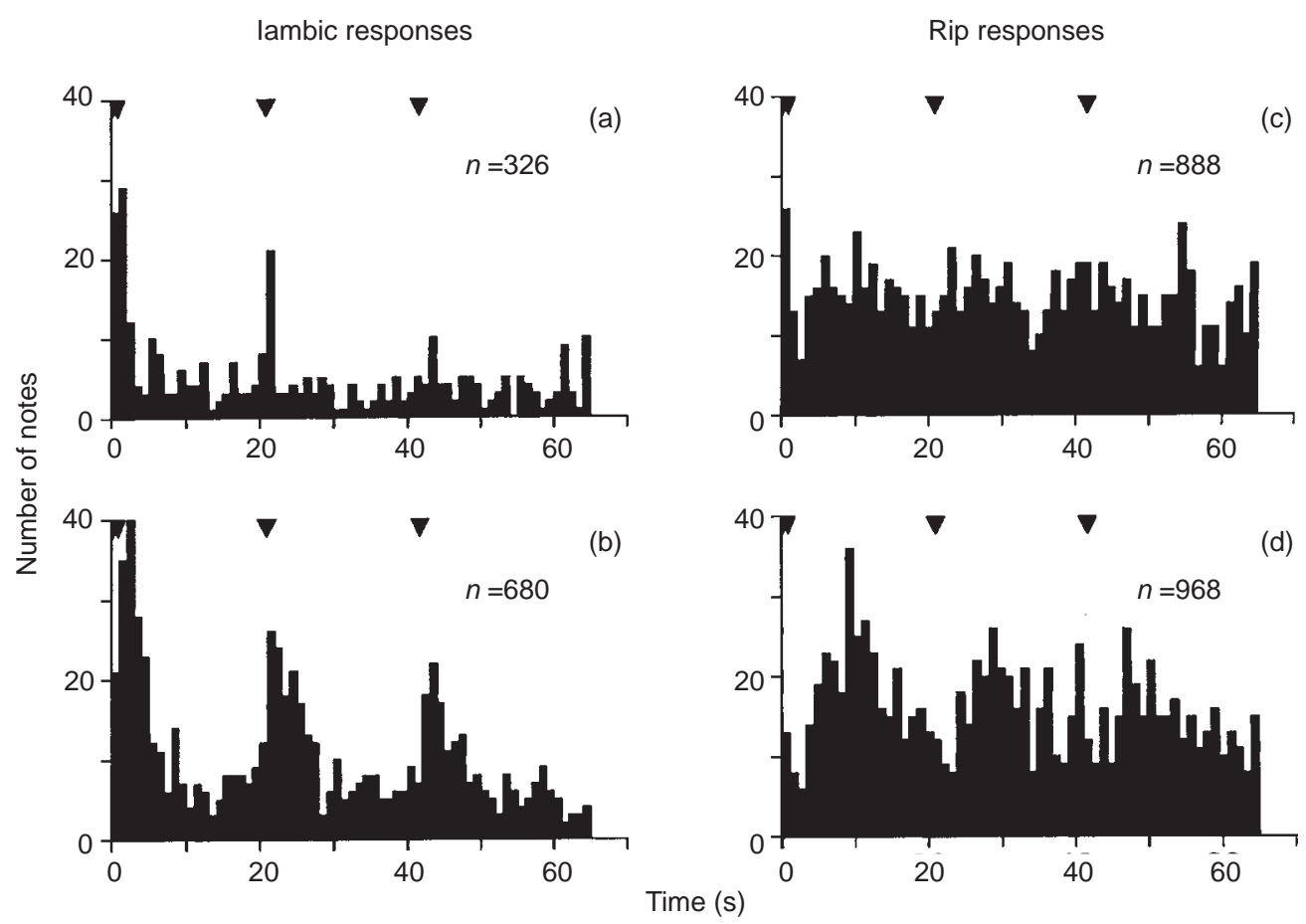

Fig. 8. Period histograms illustrating the iambic and rip responses to stimulus 3, as a function of playback level. (a), (c) level 4; (b), (d) level 6. Data are combined from five subjects. Inverted triangles indicate the onset times of each of the three syllables: rip note-plus-iambic note, iambic note alone and rip note alone, during the $66.1 \mathrm{~s}$ stimulus period. Left, onset times of iambic responses; right, onset times of rip responses. Playback levels (dB SPL) are given in the text. Bin widths of the histograms $1.0 \mathrm{~s}$.

kind to iambic notes was robust at higher stimulus levels. In contrast, the tendency to respond immediately in kind to rip notes was robust only over a narrow range of levels, those corresponding to a calling male at distances in the neighbourhood of 1-2 m, typical natural intermale distances. (Adjacent males calling along the roadside at one site were spaced at 2.0, 1.6, $1.4,1.6,1.1$ and $4.3 \mathrm{~m}$.)

Males gave clear iambic call note responses to each of the three call components of stimulus 3 , especially at the higher of the two playback levels used (Fig. 8). The synchrony of iambic responses to the rip-iambic call note complex is conspicuously greater than that to either of the other call notes. Notice the absence of rip responses during the time of peak iambic note production (the frog can make only one call note at a time). In the case of stimulus 4 (Fig. 9), the synchrony of iambic responses to the call note complex is con- spicuously greater than that to the iambic or pre-call notes alone. Moreover, at playback level 4, the three toc notes clearly inhibited the production of iambic notes from the test males, but not the production of rip notes. The other two components of stimulus 4, namely the five-pulse iambic note and the three toc notes followed by the five-pulse iambic note, had no obvious effect on the production of rips or iambic notes from the test males.

\section{Call sequence analysis}

We documented the development of one male's call note repertoire both as a function of time (Fig. 10a) and as a function of the number of notes emitted (Fig. 10b). In the first 45-min recording segment, this male produced 14 call note types in the first $12 \mathrm{~min}$ (after 110 total

Table 1. Tendency of B. madagascariensis males to respond in kind to iambic and rip call notes as a function of increasing stimulus playback levels. Absolute playback levels are given in the text. Iambic/Rip is the number of iambic call notes given during the stimulus 'on period' (first $6 \mathrm{~s}$ for stimulus 1; first $8 \mathrm{~s}$ for stimulus 2) divided by the number of rip call notes given during the same period. NS = not significant

\begin{tabular}{|c|c|c|c|c|c|c|c|c|}
\hline \multirow[b]{2}{*}{ Playback level } & \multicolumn{4}{|c|}{ Stimulus 1 (4 iambic notes) } & \multicolumn{4}{|c|}{ Stimulus 2 (4 rip notes) } \\
\hline & $n$ & Iambic/rip & $\chi^{2}$ & $P$ & $n$ & Iambic/rip & $\chi^{2}$ & $P$ \\
\hline 3 & 29 & 0.38 & 27.86 & $<0.001$ & 29 & 0.45 & 20.86 & $<0.001$ \\
\hline 4 & 112 & 1.07 & 0.24 & NS & 112 & 0.84 & 1.39 & NS \\
\hline 5 & 278 & 1.34 & 4.94 & $<0.05$ & 176 & 0.78 & 2.72 & $<0.01$ \\
\hline 6 & 296 & 2.12 & 24.82 & $<0.001$ & 132 & 0.94 & 0.19 & NS \\
\hline
\end{tabular}




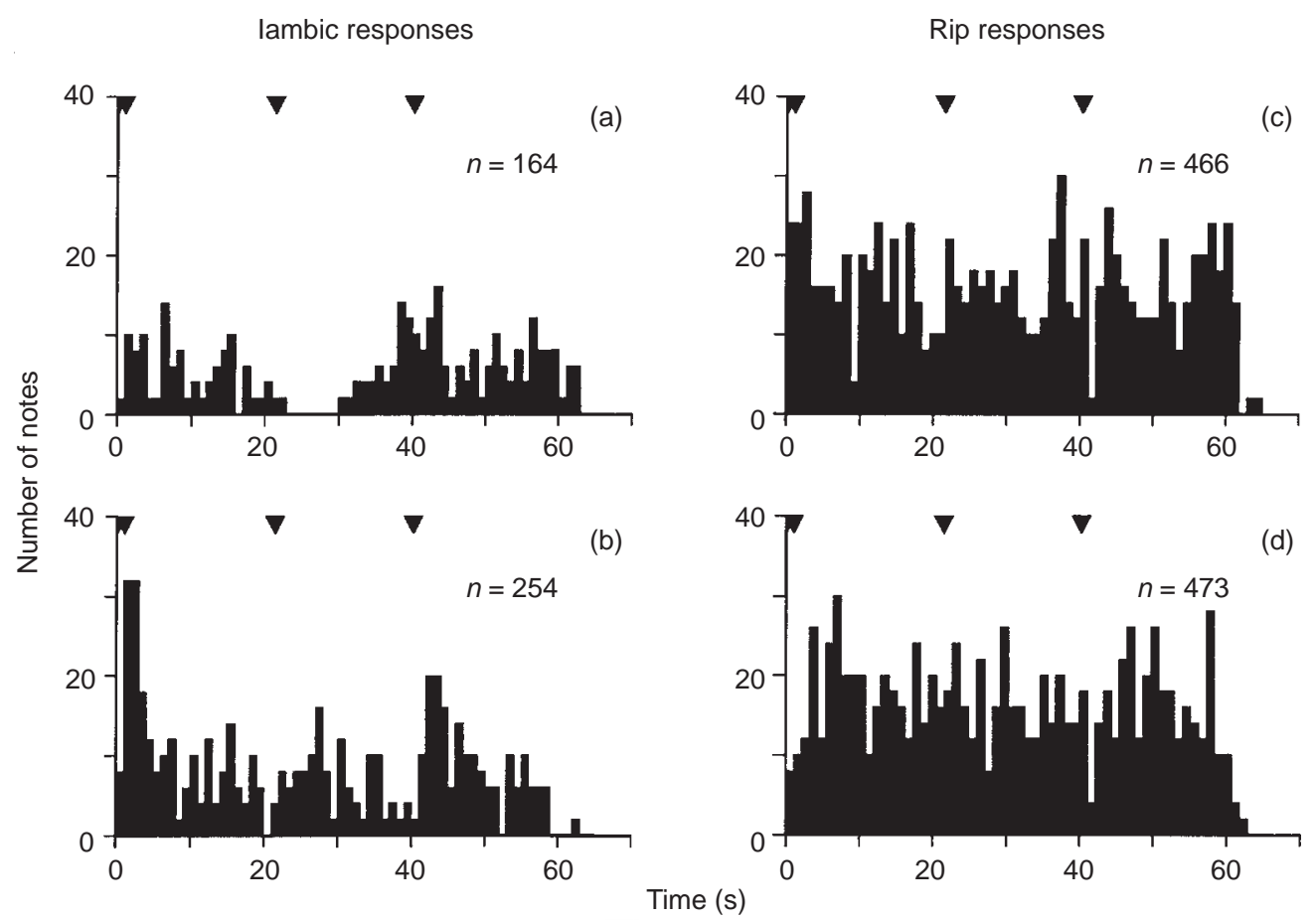

Fig. 9. Period histograms illustrating the iambic and rip responses to stimulus 4, as a function of playback level: levels same as Fig. 8. Data are combined from two subjects. Inverted triangles indicate the onset times of each of the three syllables: three toc notes-iambic note, three toc notes alone, iambic note alone, during the $57.7 \mathrm{~s}$ stimulus period. Left, onset times of iambic responses; right, onset times of rip responses. Playback levels (dB SPL) are given in the text. Bin widths of the histograms $1.0 \mathrm{~s}$.

calls), and in the second 45-min segment, he produced 12 call note types within the first $3 \mathrm{~min}$ of recording, after only 40 calls.

We recorded the spontaneous call note sequences of several calling males in order to observe patterns or consistent repetitions of particular notes. For example, using the call note labelling scheme in Fig. 3, the following represent actual spontaneous call notes sequences recorded from three individuals on three different nights:

Male 1: c,b,c,c,g,c,p,a,d,a,c,g,l,a,p,h,g,a,c;

Male 2: f,l,l,c,c,j,h,a,c,f,k,k,c,a,g,c,c,g;

Male 3: g,l,c,c,d,k,k,c,b,l,k,a,b,c,f,k,k,g,a,g,c,c,h.

Given the difficulty in detecting call note patterns from observing the sequences, we assigned each of the 28 separate call types to one of five groups, A-E using the call notation in Fig. 3 as follows: calls a,b $\Rightarrow$ A; calls $\mathrm{c}, \mathrm{d} \Rightarrow \mathrm{B}$; calls $\mathrm{e}, \mathrm{f} \Rightarrow \mathrm{C}$; call $\mathrm{g} \Rightarrow \mathrm{D}$ and calls $\mathrm{h}-\mathrm{p} \Rightarrow \mathrm{E}$. A 100 -note sequence was recorded from each of three calling males. The three sequences were tested by the permutation method to check for the occurrence of preferred call note pairs (Fig. 11). In the first two sequences, males emitted calls from all five call groups (A-E), resulting in 25 possible sequential call note pairs. In the third sequence, call type D was not produced in the 100 notes, resulting in 16 possible call note pairs. In sequence 1 , one call note pair (EC) was present significantly more than would be expected by chance; however, in sequence 2 and 3 , no call pair occurred by chance alone significantly more than would be predicted. After applying the Bonferroni test for multiple comparisons to sequence 1 , no call note pair occurred by chance more or less often than would be expected.

\section{Morphometric measurements}

The larynx of B. madagascariensis is situated between the processes of the hyoid cartilage that provide attachment sites for some of the laryngeal muscles (Fig. 12). Three sets of bilateral constrictor muscles wrap around the base of the arytenoid cartilages. The anterior and posterior laryngeal constrictor muscles attach at the caudal end of the larynx and extend rostrally attaching to the hyoid. The hyo-laryngeus muscle attaches at the rostral end of the arytenoid cartilage, extends in a ventro-lateral direction and attaches to the hyoid, lateral to the larynx. Dilator muscles attach bilaterally to the apical end of the larynx on either side of the glottal slit and extend to the lateral areas of the hyoid processes. Morphometric measurements for the specimen of B. madagascariensis studied are: snout-vent length, $47.5 \mathrm{~mm}$; head width, $19.0 \mathrm{~mm}$; mean tympanic membrane diameter, $4.69 \mathrm{~mm}$; 'spine' length on rear leg, $1.20 \mathrm{~mm}$; 'spine' length on foreleg, $1.04 \mathrm{~mm}$; glottal slit length (gross), $3.43 \mathrm{~mm}$; glottal slit length (epithelium removed), 2.60 $\mathrm{mm}$; larynx length (gross), $4.94 \mathrm{~mm}$; larynx width (gross), $3.26 \mathrm{~mm}$. 


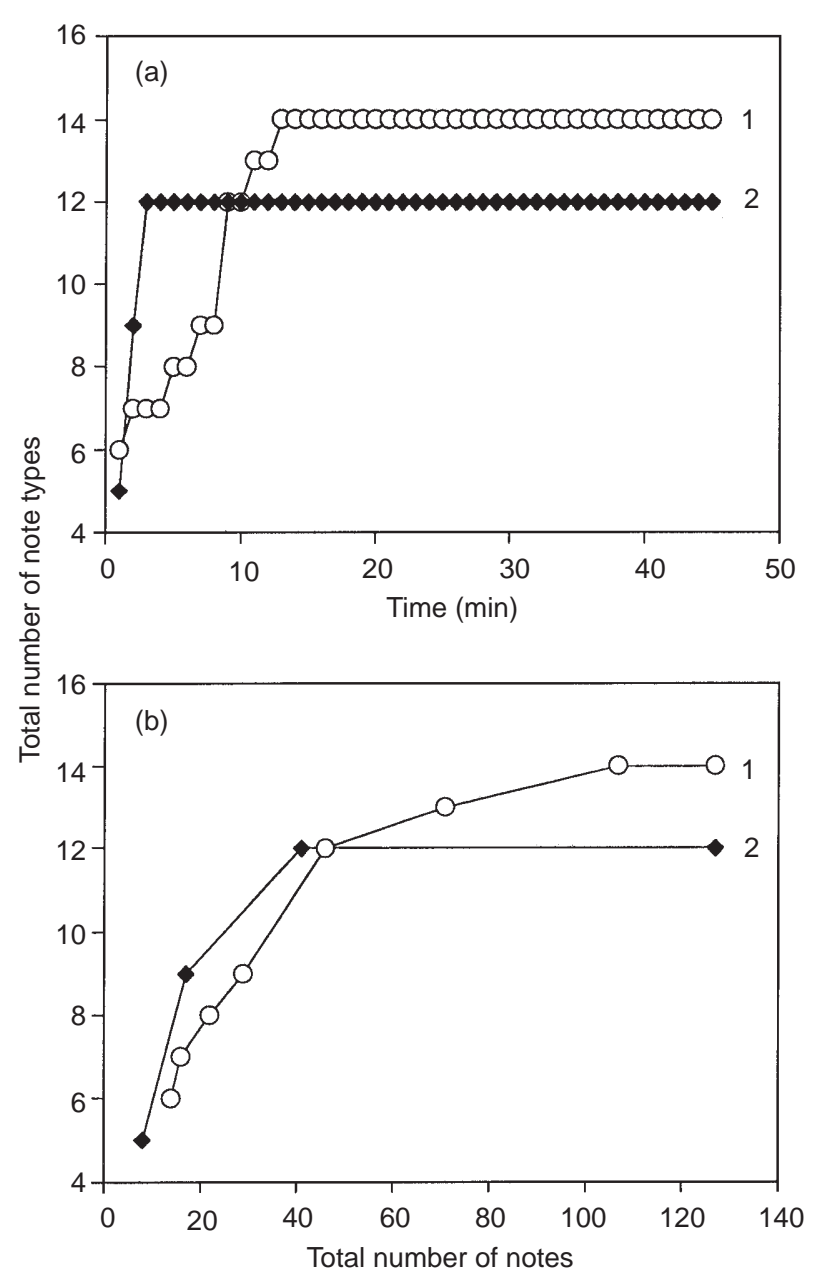

Fig. 10. Development of call note repertoire during a 90-min recording of the spontaneous calling of male no. 1. The total number of call notes produced by male no. 1: (a) as a function of time; (b) as a function of the number of notes given for the first 45-min recording period $(\bigcirc)$ and for the second 45-min period $(\diamond)$. During the first $45 \mathrm{~min}$, the male produced 14 distinct call notes, whereas during the second $45 \mathrm{~min}$, he emitted 12 distinct call notes.

\section{DISCUSSION}

How can a frog produce such a wide repertoire of call notes? Preliminary morphological analysis of the vocal musculature of $B$. madagascariensis reveals no unusual adaptations that would facilitate rapid glottal opening or closing, for example. Frog calls are generated by muscular contractions of the body wall forcing air current over the vocal cords causing them to vibrate (Martin, 1971). In general, constrictor muscle contractions and relaxations have been associated with changing the shape of the larynx, bringing the vocal cords into the airstream and affecting both temporal and spectral parameters of anuran vocalizations (Schneider, 1988; McClelland \& Hutchison, 1993; Wilczynski, McClelland \& Rand, 1993). However, vocal characteristics are affected not only by the number and anatomical positions of the laryngeal muscles

\begin{tabular}{c|c|c|c|c|c|} 
(a) & \multicolumn{1}{c}{ A } & \multicolumn{1}{c}{$\mathrm{B}$} & \multicolumn{1}{c}{$\mathrm{C}$} & \multicolumn{1}{c}{$\mathrm{D}$} & $\mathrm{E}$ \\
\cline { 2 - 6 } $\mathrm{A}$ & 0.117 & 0.873 & 0.287 & 0.430 & 0.607 \\
\cline { 2 - 6 } $\mathrm{B}$ & 0.917 & 0.717 & 0.280 & 0.440 & 0.100 \\
\cline { 2 - 6 } $\mathrm{C}$ & 0.297 & 0.047 & 0.413 & 0.317 & $0.980^{*}$ \\
\cline { 2 - 6 } $\mathrm{D}$ & 0.737 & 0.423 & 0.967 & 0.727 & 0.040 \\
\cline { 2 - 6 } $\mathrm{E}$ & 0.197 & 0.317 & 0.647 & 0.667 & 0.887 \\
\cline { 2 - 6 } & & & & &
\end{tabular}

\begin{tabular}{|c|c|c|c|c|c|}
\hline (b) & A & B & C & D & E \\
\hline A & 0.957 & 0.533 & 0.433 & 0.297 & 0.270 \\
\hline B & 0.167 & 0.520 & 0.830 & 0.460 & 0.813 \\
\hline C & 0.407 & 0.833 & 0.473 & 0.460 & 0.270 \\
\hline D & 0.283 & 0.673 & 0.457 & 0.973 & 0.107 \\
\hline E & 0.483 & 0.473 & 0.263 & 0.357 & 0.677 \\
\hline
\end{tabular}

(c)

\begin{tabular}{c|c|c|c|c|}
\multicolumn{1}{c}{} & \multicolumn{1}{c}{ A } & \multicolumn{1}{c}{ B } & \multicolumn{1}{c}{ C } & \multicolumn{1}{c}{ E } \\
\cline { 2 - 5 } A & 0.560 & 0.930 & 0.373 & 0.120 \\
\cline { 2 - 5 } B & 0.957 & 0.420 & 0.897 & 0.107 \\
\cline { 2 - 5 } C & 0.380 & 0.903 & 0.467 & 0.197 \\
\cline { 2 - 5 } E & 0.050 & 0.250 & 0.227 & 0.930 \\
\cline { 2 - 5 } & & & &
\end{tabular}

Fig. 11. Probability matrices for sequential pairs for three sequences (a)-(c) of 100 spontaneous call notes from three males of B. madagascariensis. The columns represent the first call note of the pair and the rows represent the second call note. Using a two-tailed analysis, only pair EC $\left(^{*}\right)$ in the first sequence occurred with a probability greater than would have occurred by chance alone at the $P<0.05$ level. However, when the number of comparisons being made is taken into account, no call note pair occurred by chance alone with a probability greater than would be expected.

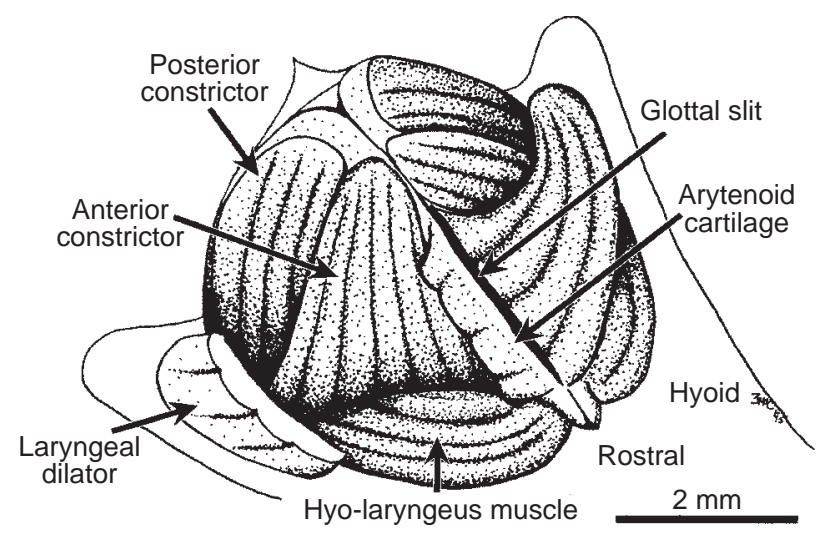

Fig. 12. The intact, isolated larynx of a male B. madagascariensis shown with the superficial epithelial tissue and dilator muscle removed to expose the laryngeal musculature.

(Steinwarz, 1990), but also by the patterns of neural excitation driving the muscles. For example, Schneider (1970) found that the European treefrogs Hyla a. arborea and $H$. meridionalis emit different advertisement calls despite the morphological similarity of the larynx in these two species. Thus, the possibility exists that the 

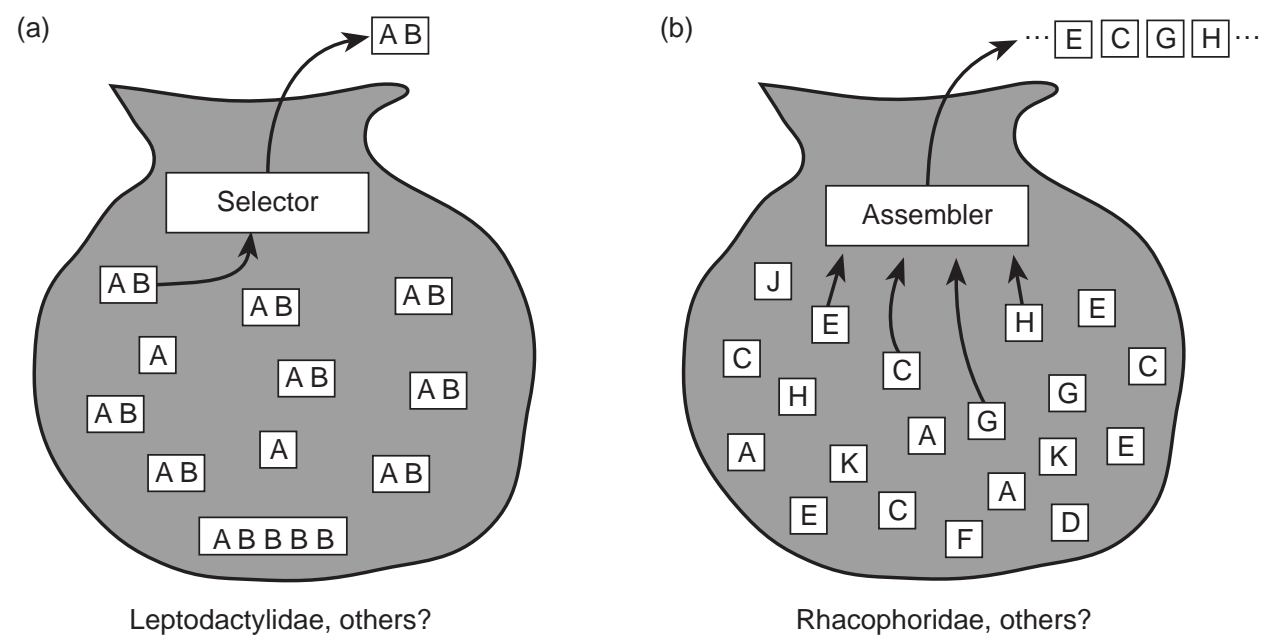

Fig. 13. Putative call generation schemes for two families of frogs. Frog calls of males in the Leptodactylidae (a) seem to be selected from a fixed set of pre-packaged call notes and call note sequences. In contrast, many frogs in the Old World Rhacophoridae (b) seem to assemble call sequences from a greater variety of potential call notes in no fixed order. See text for details.

hyperextended vocal repertoire in this species is the result of divergent neural input to the larynx, which may reflect species differences in the neural circuitry driving the larynx.

Many neotropical frogs in the Hylidae and Leptodactylidae produce stereotyped vocalizations. In these families there are species for which vocal repertoire has been characterized and extensively studied. For example, males of the Puerto Rican coqui Eleutherodactylus coqui (Leptodactylidae) produce a stereotyped, two-note call in which the first (Co) note is used by males in aggressive interactions whereas the second (Qui) note is used to attract females (Narins \& Capranica, 1976). In that species, the Co note is produced either alone or followed by the Qui note. The Qui note is never given alone, and moreover the Qui note never precedes the Co note, i.e. the temporal order of the notes is fixed (Narins \& Capranica, 1978). A fixed temporal note order and a relatively small number of stereotyped call types is the rule in many species of hylids and leptodactylids (Ryan, 1980; Schwartz \& Wells, 1984a; Wells \& Schwartz, 1984a, $b$; Harrison \& Littlejohn, 1985). It is helpful for us to think about these calls as being 'selected' from a store of prepackaged calls and broadcast. Rhacophorids, in contrast, are known to produce a relatively large number of call notes (Schiøtz, 1967; Arak, 1983; Kuramoto, 1986; Kasuya, Kumaki \& Saito, 1992; Andreone, 1993; Matsui \& Wu, 1994; Jehle \& Arak, 1998; Narins et al., 1998), although there are clearly some exceptions (Kanamadi et al., 1993). The ability of males of several species in the family Rhacophoridae to produce a great number of distinct call note types in no predictable order suggests an alternate scheme for thinking about the mechanisms underlying call note generation (Fig. 13). We have observed that B. madagascariensis seems to be able to choose single call notes from a (relatively large) pool and assemble them into long sequences in which call note pairs occur in no predictable order. In this sense, B. madagascariensis is unusual but perhaps not unique among frogs.

The total number of call notes comprising a frog's vocal repertoire varies from species to species. The extent of the vocal repertoire reflects the selection pressure for premating reproductive isolation within the species, the ecological environment in which it resides, and the development of its social behavior (Capranica, 1976). The discovery of a frog with the ability to produce at least 28 different call notes suggests the existence of a relatively sophisticated signaling system. This may be interpreted as an extension of the graded call repertoires identified in several other species studied (Schwartz \& Wells, 1984a,b, 1985; Schwartz, 1986). This interpretation would implicate the various iambic call notes as reflective of different levels of aggression, and is supported by the following preliminary observations: (1) the lack of clear gaps between iambic note types; (2) the relatively low frequency of iambic note occurrence in the recorded sequences of spontaneous calls; (3) the relatively high frequency of iambic note occurrence in the recorded sequences of stimulusevoked calls; (4) other rhacophorid or closely related hyperoliid frogs have trilled or pulsed aggressive calls that appear to be graded (Schiøtz, 1967; Arak, 1983; Grafe, 1995). However, we believe that more data are needed to substantiate this interpretation of the function of the iambic call notes in this species.

What could be the significance of a large vocal repertoire? The avian literature provides several possible answers including: (1) repertoires are a product of sexual selection; male mockingbirds with large repertoires hold higher quality territories and mate earlier than those with smaller repertoires (Howard, 1974). In addition, Catchpole (1980) demonstrated that male sedge warblers in a marked population with larger repertoires paired earlier than conspecifics with more 
simple songs. (2) The Beau Geste hypothesis (Krebs, 1977); this idea presumes that the caller is territorial and that an intruder to the territory will assess the density of birds already present by listening to song. If a territorial male can create the impression of a crowded habitat by singing different songs, new arrivals will assess suitability as low and settle elsewhere (Krebs, 1977). (3) Repertoires allow matched countersinging; in several bird species males will match song types when countersinging (Hinde, 1958; Lemon, 1968). If matching during countersinging aids in territory maintenance, a repertoire of songs (or call notes) would be important to allow matching with many individuals (Krebs, 1977).

We found that choruses of B. madagascariensis males often appeared to have a leader - one frog that would begin calling with a short, initial (or 'preface') call note followed by an iambic note. Based on this observation, we hypothesized that the neighbouring (follower) frogs would preferentially synchronize the production of their calls with the preface-plus-iambic note. Directly testing this hypothesis with playback experiments confirmed this subjective impression: synchrony was greatest to the complete leader call and less to either the preface or iambic note presented alone. Thus, the preface note may function as an 'alerting' component as in the call repertoire of rufous-sided towhees, sensu Richards (1981).

In his comprehensive study of the neotropical frog Physalemus pustulosus, Ryan (1985) suggested that call diversity or call complexity increases the attractiveness of the caller. Although our data do not address female preference of different call notes, they do provide preliminary evidence for matched counter-calling by males. This phenomenon has been well-documented in several species of anurans: Philautus leucorhinus, P. variabilis, Rhacophorus microtympanus (Arak, 1983); Hyla microcephala (Schwartz, 1986) and Hyperolius tuberilinguis (Pallett \& Passmore, 1988). We have demonstrated that playback of the males' own call notes may result in increasing, decreasing or non-changed calling rates from the males under test. Moreover, there is some evidence that playback of particular call notes results in a higher probability of the test male producing those same call notes in response. Matched counter-calling can function to maintain territories and to identify conspecifics in a multispecific assemblage. Another possibility, suggested by Arak (1983) and Jehle \& Arak (1998) is that matched counter-calling is the outcome of the way in which males modify the energy spent on advertisement in relation to the degree of acoustic competition that they perceive in the chorus. Thus, when a male emits a longer, presumably more attractive call, his neighbour is forced to increase the duration of his call to match or exceed that of the competitior. They speculate that this would naturally lead to the evolution of a graded communication system. The large call note repertoire of Boophis and its unpredictable delivery sequence is unprecedented in anurans, and may provide the basis for understanding the neural control of vertebrate vocalizations.

\section{Acknowledgements}

The authors thank Dr Patricia Wright from the Institute for the Conservation of Tropical Environments for her support of our project. David Narins also assisted in getting the project off the ground. We thank Eva Hecht, Wei Huang, Lisa Garcia and Hoang Nguyen who aided with data analysis. We are grateful to Margaret Kowalczyk and Alejandro Purgue for assistance with the figure production, and to Jakob ChristensenDalsgaard, Anthony Arak and an anonymous reviewer for helpful comments on the manuscript. Thanks are also due to Benjamin Andriamihaja, Gervais Sylvestre Rakotoarivelo, Richard Randriamampionona and Freddy Raymond for logistical support in the field. This research was supported by a Guggenheim Fellowship and NIDCD Grant no. DC00222 to PMN and NIDCD Grant no. DC00112 to ERL.

\section{REFERENCES}

Adams, D. C. \& Anthony, C. D. (1996). Using randomization techniques to analyse behavioural data. Anim. Behav. 51: 733-738.

Andreone, F. (1993). Two new treefrogs of the genus Boophis (Anura: Rhacophoridae) from central-eastern Madagascar. Boll. Mus. Reg. Sci. Nat. Torino 11: 289-313.

Andreone, F. (1994). The amphibians of Ranomafana rain forest, Madagascar - preliminary community analysis and conservation considerations. Oryx 28: 207-214.

Andreone, F. (1996). Seasonal variations of the amphibian communities in two rainforests of Madagascar. In Biogéographie de Madagascar: 397-402. Lourenço, W. R. (Ed.). Paris: Orstom Éditions.

Arak, A. (1983). Vocal interactions, call matching and territoriality in a Sri Lankan treefrog, Philautus leucorhinus (Rhacophoriade). Anim Behav. 31: 292-302.

Blommers-Schlösser, R. M. A. (1979). Biosystematics of the malagasy frogs. II. The genus Boophis (Rhacophoridae). Bijdr. Dierkd. 49: 261-312.

Bogert, C. M. (1960). The influence of sound on the behavior of amphibians and reptiles. In Animal sounds and communication: 137-320. Lanyon, W. E. \& Tavolga, W. N. (Eds). Washington, D.C.: A.I.B.S.

Brenowitz, E. A., Wilczynski, W. \& Zakon, H. H. (1984). Acoustic communication in spring peepers. Environmental and behavioral aspects. J. Comp. Physiol. 155: 585-592.

Capranica, R. R. (1968). The vocal repertoire of the bullfrog (Rana catesbeiana). Behaviour 31: 302-325.

Capranica, R. R. (1976). The auditory system. In Physiology of the amphibia III: 443-466. Lofts, B. (Ed.). New York: Academic Press.

Catchpole, C. K. (1980). Sexual selection and the evolution of complex songs among warblers of the genus Acrocephalus. Behaviour 74: 149-166.

Gerhardt, H. C. \& Klump, G. M. (1988). Masking of acoustic signals by the chorus background noise in the green tree frog: a limitation on mate choice. Anim. Behav. 36: 1247-1249.

Given, M. F. (1987). Vocalizations and acoustic interactions of the carpenter frog, Rana virgatipes. Herpetologica 43: 467481.

Glaw, F. \& Vences, M. (1994). A fieldguide to the amphibians and reptiles of Madagascar (including mammals and freshwater fish). 2nd edn. Köln: M. Vences \& F. Glaw Verlags GbR. 
Goodman, S. M., Creighton, G. K. \& Raxworthy, C. (1991). The food habits of the Madagascar long-eared owl Asio madagascariensis in southeastern Madagascar. Bonn. Zool. Beitr. 42: 21-26.

Grafe, T. U. (1995). Graded aggressive calls in the African painted reed frog Hyperolius marmoratus (Hyperoliidae). Ethology 101: $67-81$.

Harrison, P. A. \& Littlejohn, M. J. (1985). Diphasy in the advertisement calls of Geocrinia laevis (Anura: Leptodactylidae): vocal responses of males during field playback experiments. Behav. Ecol. Sociobiol. 18: 67-73.

Hinde, R. A. (1958). Alternative motor patterns in chaffinch song. Anim. Behav. 6: 211-218.

Howard, R. D. (1974). The influence of sexual selection and interspecific competition on mockingbird song. Evolution 28: 428-438.

Jehle, R. \& Arak, A. (1998). Graded call variation in the Asian cricket frog Rana nicobariensis Bioacoustics. 9: 35-48.

Kanamadi, R. D., Schneider, H., Hiremath, C. R. \& Jirankali, C. S. (1993). Vocalization of the tree frog Polypedates maculatus (Rhacophoridae). J. Biosci. 18: 239-245.

Kasuya, E., Kumaki, T. \& Saito, T. (1992). Vocal repertoire of the Japanese treefrog, Rhacophorus arboreus (Anura: Rhacophoridae). Zool. Sci. 9: 469-473.

Krebs, J. R. (1977). The significance of song repertoires: the Beau Geste hypothesis. Anim. Behav. 25: 475-478.

Kuramoto, M. (1986). Call structure of the rhacophorid frogs from Taiwan. Sci. Report Lab. Amphib. Biol. Hiroshima Univ. 8: $45-68$.

Lemon, R. E. (1968). The relation between organisation and function of song in cardinals. Behaviour 32: 158-178.

Littlejohn, M. J. (1977). Long-range acoustic communication in anurans: an integrated and evolutionary approach. In The reproductive biology of amphibians: 263-294. Taylor, D. H. \& Guttman, S. I. (Eds). New York: Plenum Press.

Martin, W. F. (1971). Mechanics of sound production in toads of the genus Bufo: passive elements. J. exp. Zool. 176: 273-294.

Matsui, M. \& Wu, G.-F. (1994). Acoustic characteristics of treefrogs from Sichuan, China, with comments on systematic relationships of Polypedates and Rhacophorus (Anura: Rhacophoridae). Zool. Sci. 11: 485-490.

McClelland, B. E. \& Hutchison,V. H. (1993). Laryngeal anatomy and morphology in goliath frogs. Am. Soc. Icthyol. Herpetol. Mtg. Univ. Texas, Austin, abstr. 215.

McDiarmid, R. W. \& Adler, K. (1974). Notes on territorial and vocal behavior of neotropical frogs of the genus Centrolenella. Herpetologica 30: 75-78.

Narins, P. M. (1982). Effects of masking noise on evoked calling in the Puerto Rican Coqui (Anura: Leptodactylidae). J. comp. Physiol. 147: 439-446.

Narins, P. M. \& Capranica, R. R. (1976). Sexual differences in the auditory system of the tree frog Eleutherodactylus coqui. Science 192: 378-380.

Narins, P. M. \& Capranica, R. R. (1977). An automated technique for analysis of temporal features in animal vocalizations. Anim. Behav. 25: 615-621.

Narins, P. M. \& Capranica, R. R. (1978). Communicative significance of the two-note call of the treefrog, Eleutherodactylus coqui. J. comp. Physiol. 127: 1-9.

Narins, P. M., Feng, A. S., Yong, H.-S. \& Christensen-Dalsgaard, J. (1998). Morphological, behavioral and genetic divergence of sympatric morphotypes of the treefrog Polypedates leucomystax in Peninsular Malaysia. Herpetologica 54: 129-142.

Narins, P. M. \& Lewis, E. R. (1996). Extended call repertoire of a Madagascar frog. In Biogéographie de Madagascar: 403-410. Lourenço, W. R. (Ed.). Paris: Orstom Éditions.

Narins, P. M. \& Zelick, R. (1988). The effects of noise on auditory processing and behavior in amphibians. In The evolution of the amphibian auditory system: 511-536. Fritzsch, B., Ryan, M. J., Wilczynski, W., Hetherington, T. E. \& Walkowiak, W. (Eds). New York: John Wiley.

Nicoll, M. E. \& Langrand, O. (1989). Madagascar: revue de la Conservation et des Aires Protégées. Gland, Switzerland: WWF.

Pallett, J. R. \& Passmore, N. I. (1988). The significance of multinote advertisement calls in a reed frog, Hyperolius tuberilinguis. Bioacoustics 1: 13-23.

Peters, W. (1874). Über neue Amphibien. (Gymnopis, Syphonops, Polypedates, Rhacophorus, Hyla, Cyclodus, Euprepes, Clemmys). Mber K. preuss. Akad. Wiss. Berlin 1874: 616-624.

Preston-Mafham, K. (1991). Madagascar - a natural history. Oxford: Facts on File.

Rand, A. S. \& Ryan, M. J. (1981). The adaptive significance of a complex vocal repertoire in a neotropical frog. Z. Tierpsychol. 57: 209-214.

Richards, D. G. (1981). Alerting and message components in songs of rufous-sided towhees. Behaviour 76: 223-249.

Ryan, M. J. (1980). Female mate choice in a neotropical frog. Science 209: 523-525.

Ryan, M. J. (1985). The túngara frog. Chicago: Chicago University Press.

Salthe, S. N. \& Mecham, J. S. (1974). Reproductive and courtship patterns. In The physiology of the amphibia: 309-521. Lofts, B. (Ed.). New York: Academic Press.

Schiøtz, A. (1967). The treefrogs (Rhacophoridae) of West Africa. Spolia Zool. Mus. Haun. (Copenhagen) 25: 1-346.

Schneider, H. (1970). Morphologie des Larynx von Hyla a. arborea (L.) und Hyla meridionalis Böttger (Amphibia, Anura). Z. Morph. Tiere 66: 209-309.

Schneider, H. (1988). Peripheral and central mechanisms of vocalization. In The evolution of the amphibian auditory system: 537-558. Fritzsch, B., Ryan, M. J., Wilczynski, W., Hetherington, T. E. \& Walkowiak, W. (Eds). New York: John Wiley.

Schwartz, J. J. (1986). Mating call behavior and female choice in the neotropical treefrog Hyla microcephala. Ethology 73: $116-127$.

Schwartz, J. J. (1989). Graded aggressive calls of the spring peeper, Pseudacris crucifer. Herpetologica 45: 172-181.

Schwartz, J. J. \& Wells, K. D. (1984a). Interspecific acoustic interactions of the neotropical treefrog Hyla ebraccata. J. comp. Physiol. 14: 211-224.

Schwartz, J. J. \& Wells, K. D. (1984b). Vocal behavior of the neotropical treefrog Hyla phlebodes. Herpetologica 40: 452-463.

Schwartz, J. J. \& Wells, K. D. (1985). Intra- and interspecific vocal behavior of the neotropical treefrog Hyla microcephala. Copeia 1985: 27-38.

Steinwarz, D. (1990). Morphology of the larynx of the banana frog Afrixalus fornasinii (Bianconi) (Anura). Amphib.-Reptilia 11: $53-59$.

Tuttle, M. D. \& Ryan, M. J. (1982). The role of synchronized calling, ambient light, and ambient noise in anti-bat-predator behavior of a treefrog. Behav. Ecol. Sociobiol. 11: 125-131.

Wagner, W. E., Jr. (1989). Graded aggressive signals in Blanchard's cricket frog: vocal responses to opponent proximity and size. Anim. Behav. 38: 1025-1038.

Wells, K. D. (1977). The social behaviour of anuran amphibians. Anim. Behav. 25: 666-693.

Wells, K. D. (1978). Territoriality in the green frog (Rana clamitans): vocalizations and agonistic behaviour. Anim. Behav. 26: $1051-1063$.

Wells, K. D. (1988). The effect of social interactions on anuran vocal behavior. In The evolution of the amphibian auditory system: 433-454. Fritzsch, B., Ryan, M. J., Wilczynski, W., Hetherington, T. E. \& Walkowiak, W. (Eds). New York: John Wiley. 
Wells, K. D. (1989). Vocal communication in a neotropical frog Hyla ebraccata: responses of males to graded aggressive calls. Copeia 1989: 461-466.

Wells, K. D. \& Schwartz, J. J. (1984a). Vocal communication in a neotropical treefrog, Hyla ebraccata: advertisement calls. Anim. Behav. 32: 405-420.
Wells, K. D. \& Schwartz, J. J. (1984b). Vocal communication in a neotropical treefrog, Hyla ebraccata: aggressive calls. Behaviour 91: $128-145$.

Wilczynski, W., McClelland, B. E. \& Rand, A. S. (1993). Acoustic, auditory, and morphological divergence in three species of neotropical frog. J. comp. Physiol. 172: 425-438. 